Supplementary material:

\title{
Angle-Independent Structurally Colored PS@ Film with Excellent Underwater Superoleophobicity in Harsh Environments
}

\author{
Yu Xue, Fen Wang, * Yi Qin, Bo Lu, Lei Wang, Jianfeng Zhu
}

School of Materials Science and Engineering, Shaanxi University of Science

\& Technology, Xi'an, 710021, PR China

*Corresponding author:

Fen Wang,

E-mail: wangf@sust.edu.cn. Tel.: +8615114805183. 


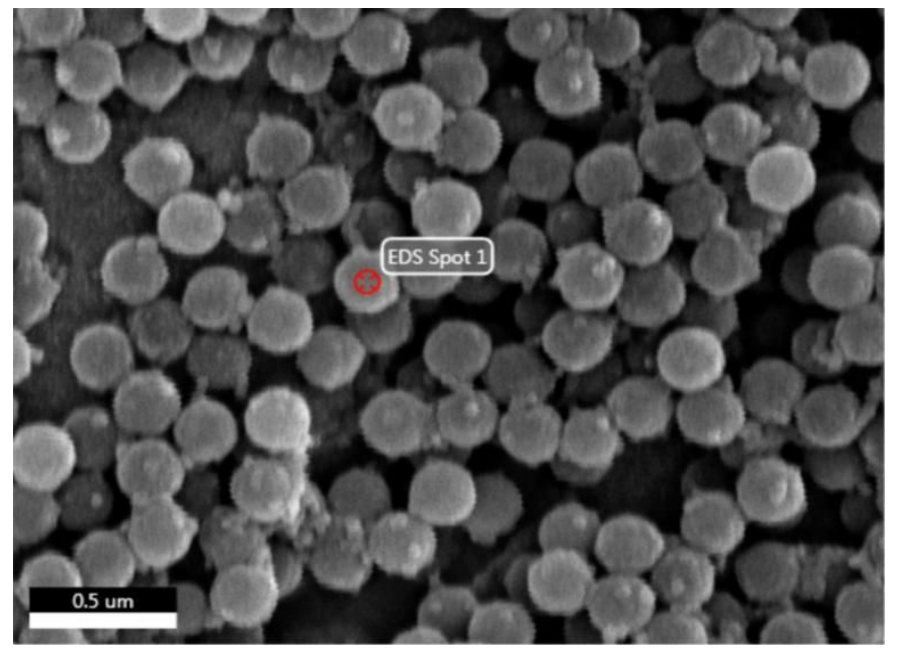

EDS area of colorful films sprayed from PS@ $\mathrm{TiO}_{2} \mathrm{NPs} / \mathrm{CB}$.

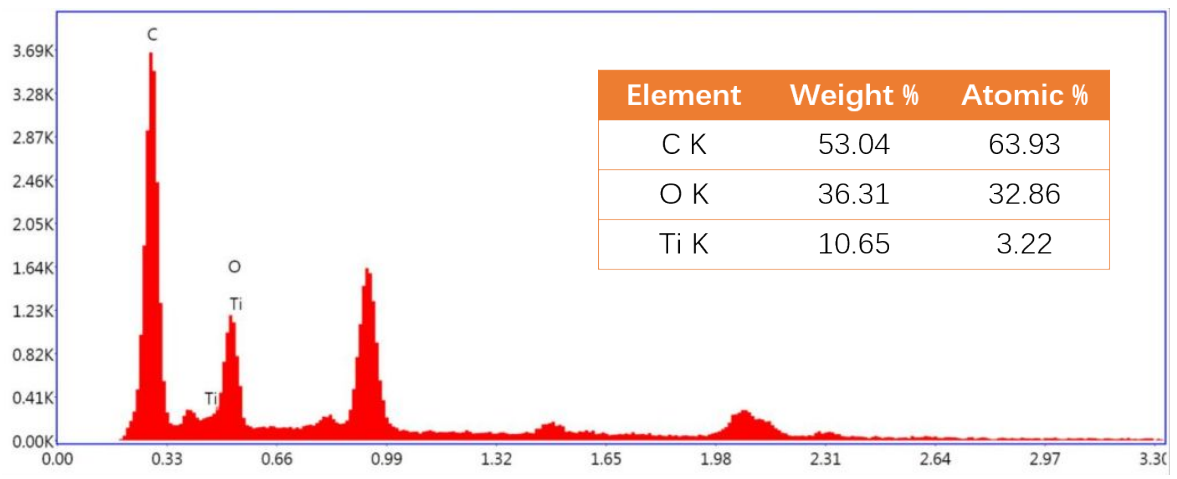

Fig. S1 EDS of colorful films sprayed from PS@ $\mathrm{TiO}_{2}$ NPs/CB. EDS of colorful films sprayed from PS@ $\mathrm{TiO}_{2} \mathrm{NPs} / \mathrm{CB}$ indicates the existence of $\mathrm{C}, \mathrm{Ti}$, and $\mathrm{O}$. 


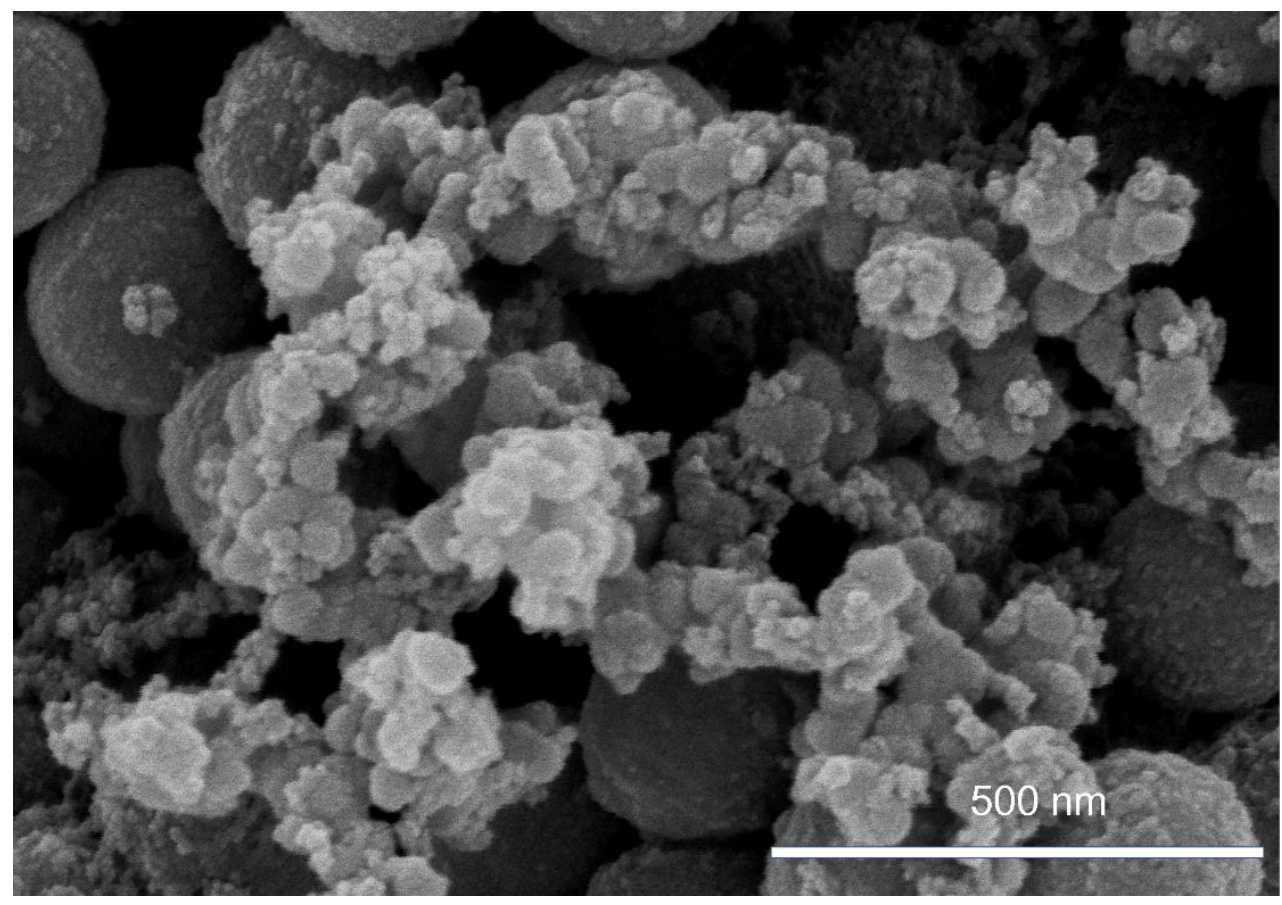

Fig. S2 SEM of spray coated films under higher magnification. 


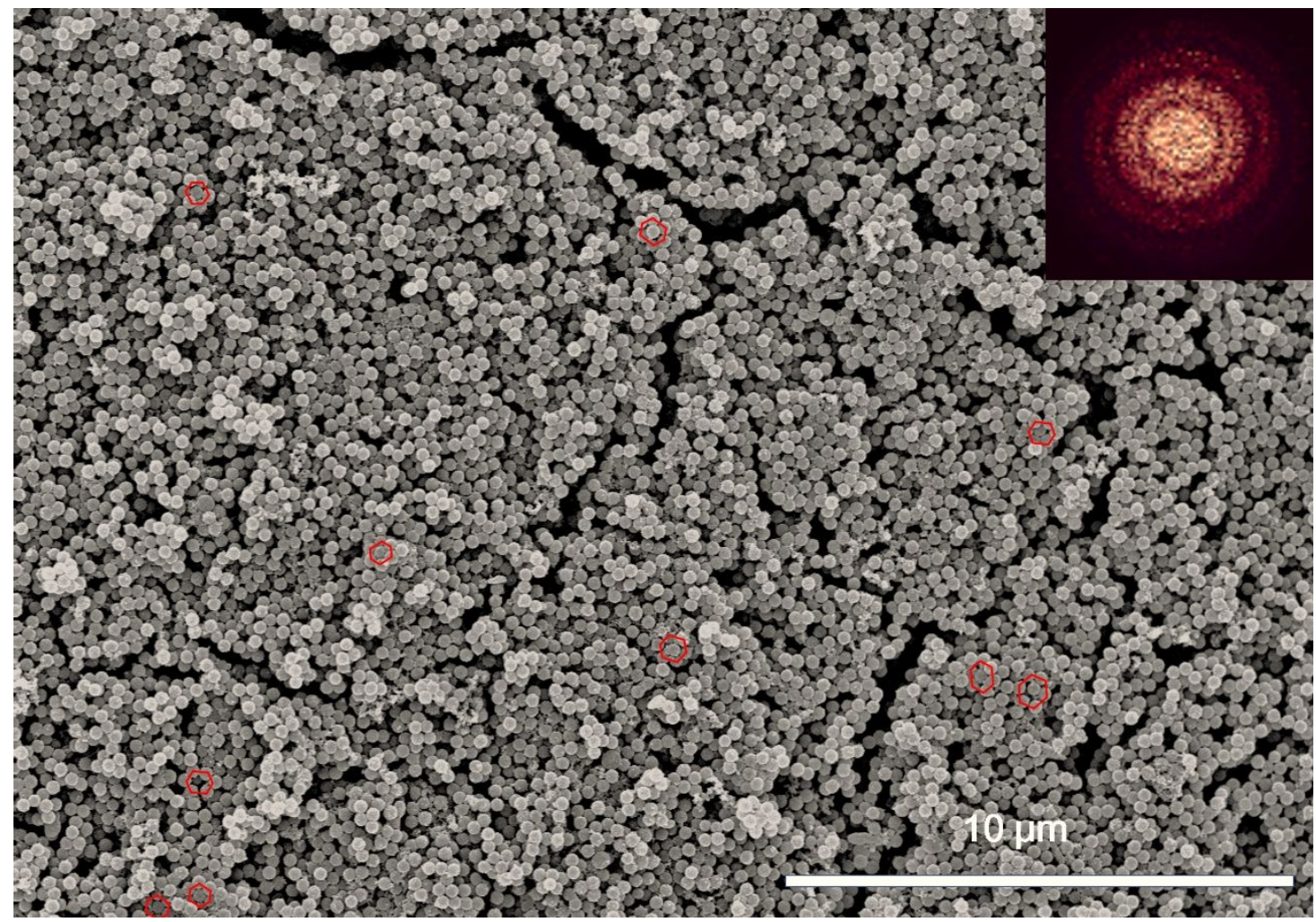

Fig. S3 SEM images of PS@ $\mathrm{TiO}_{2}$ NPs/CB film. Two-dimensional Fourier Transform of the scanning electron microscope image (Insert in Fig. S3). 


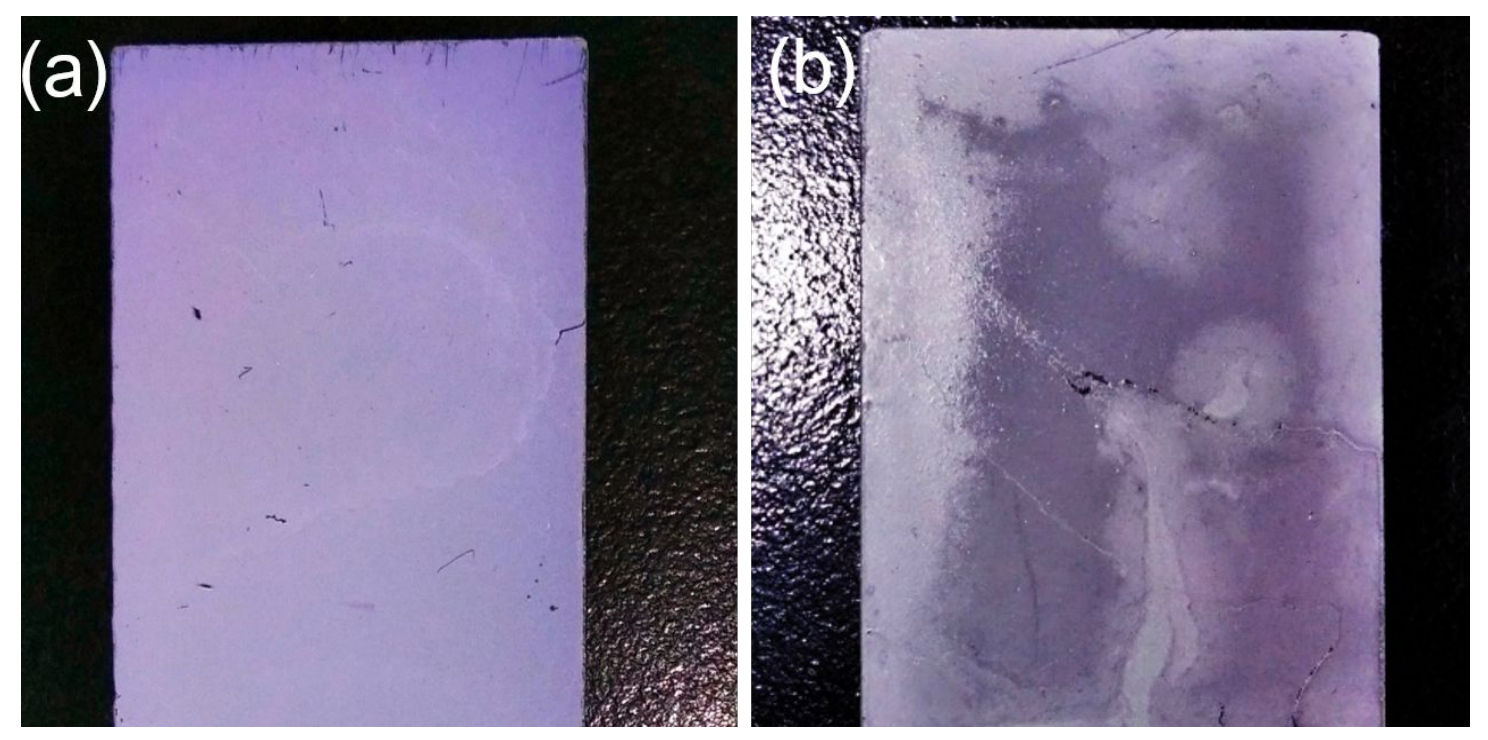

Fig. S4 Images of changes of structurally colored films with WBPU increased: (a) 2.0 wt $\%$, (b) 10 wt $\%$. 

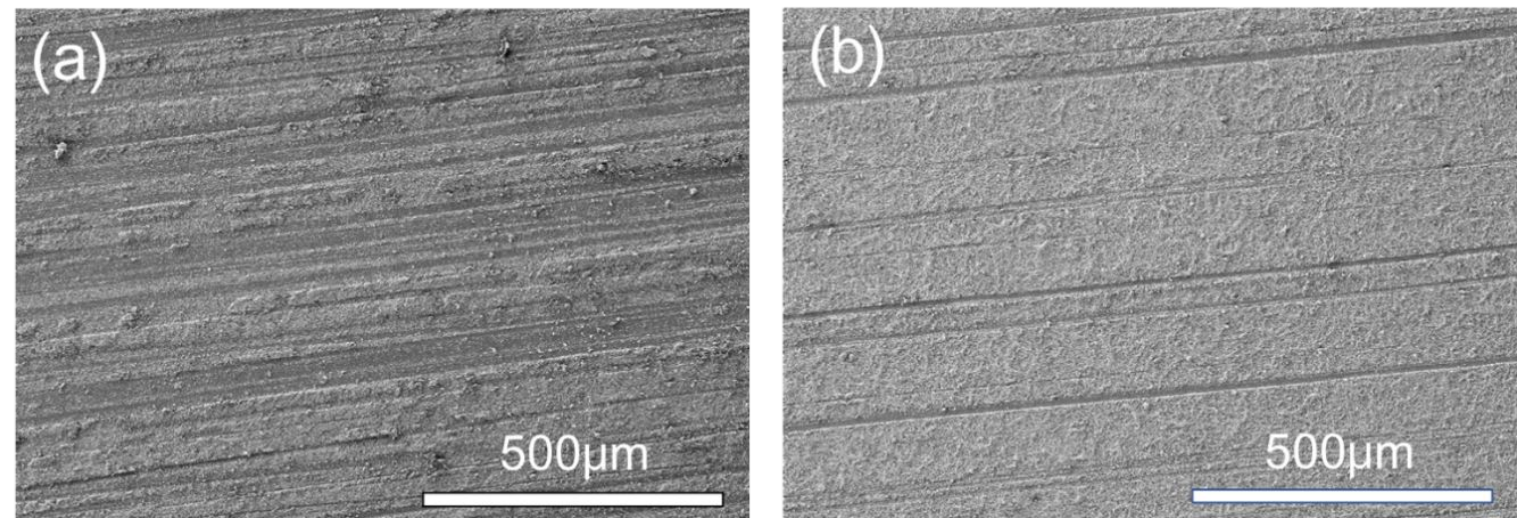

Fig. S5 SEM of colored films after scraping experiments (a) without and (b) with WBPU. 
Table S1.

Table S1. diameter and reflection peaks of PS and PS@ $\mathrm{TiO}_{2}$ photonic crystals

\begin{tabular}{ccccc}
\hline Core size & Ref peak $(\mathrm{cal})$ & $\mathrm{D}_{\text {PS@TiO2 }}$ & Ref peak(exp) & Ref peak(cal) \\
$(\mathrm{nm})$ & $(\mathrm{nm})$ & $(\mathrm{nm})$ & $(\mathrm{nm})$ & $(\mathrm{nm})$ \\
\hline 275 & 655 & 290 & 610 & 584 \\
225 & 536 & 240 & 520 & 489 \\
185 & 441 & 200 & 430 & 410 \\
\hline
\end{tabular}

